\title{
Compliance of Healthcare Workers with Hand Hygiene Practices in the Northeast of Iran: An Overt Observation
}

\author{
Reza Vafaei Nezhad ${ }^{1}$, Atieh Yaghoubi ${ }^{2}$, Kiarash Ghazvini ${ }^{3}$ \\ ${ }^{1}$ Mashhad University of Medical Sciences, Mashhad, Iran \\ ${ }^{2,3}$ Antimicrobial Resistance Research Center, Buali Research Institute, Mashhad University of Medical Sciences, Iran \\ ${ }^{2,3}$ Department of Microbiology and Virology, Faculty of Medicine, Mashhad University of Medical Sciences, Iran
}

\begin{tabular}{l} 
Article Info \\
\hline Article history: \\
Received Jul 8, 2018 \\
Revised Oct 24, 2018 \\
Accepted Nov 11, 2018 \\
\hline
\end{tabular}

\section{Keyword:}

Compliance

Hand hygiene

Healthcare worker

Iran

\begin{abstract}
Hand hygiene $(\mathrm{HH})$ is one of the most effective methods to prevent transmission and spread of microorganisms from one patient to another, also, it used to reduce the spread of pathogens in clinical settings and to help control outbreaks but compliance is usually poor. The purpose of this study was to analyze the compliance of hand hygiene and affecting factors among healthcare workers (HCWs) of northeast hospitals in Iran. This study was conducted based on observation method for the compliance of hand hygiene according to the World Health Organization (WHO) guidelines. HCWs were observed during routine patient care in different shifts, also the technique of hand hygiene was assessed through hand washing with alcohol-based disinfectant. Data were collected during 1 year, from June 2014 to July 2015 by the infection control teams in the northeast hospital of Iran. By direct observation, we evaluated a total of 92518 hand hygiene opportunities from 29 hospitals in the northeast of Iran during 1 year, with overall compliance rates in these hospitals were $43.42 \%$. Compliance rates differed by role: nurses $43 \%$, doctors $19 \%$ and other health workers $29 \%$. In this observational study, we identified that adherence to hand hygiene practice and use of alcohol-based disinfectant was very low in this hospitals, so effective intervention programs to promote adherence to hand hygiene and use of disinfectants could be effective to increase compliance.
\end{abstract}

Copyright $(2018$ Institute of Advanced Engineering and Science. All rights reserved.

\section{Corresponding Author:}

Kiarash Ghazvini,

Antimicrobial Resistance Research Center,

Buali Research Institute, Department of Microbiology and Virology, Faculty of Medicine,

Mashhad University of Medical Sciences, Mashhad, Iran.

Email: Ghazvinik@mums.ac.ir

\section{INTRODUCTION}

Hand hygiene $(\mathrm{HH})$ is one of the most effective methods to prevent transmission of microorganisms from one patient to another, also it is one of the most useful programs to control the infection in healthcare facilities but compliance is usually poor [1,2]. According to the hand wash guideline of WHO and CDC, it could be better if healthcare workers wash their hands with soap and water routinely, also, alcohol-based disinfectant is recommended when soap and water washing was unavailable [3-5]. The aim of this study is to consider the compliance of hand hygiene and factors which influence its adherence among the HCWs in 29 hospitals in the northeast of Iran.

\section{METHOD}

This observational study was performed in 29 private and governmental hospitals in northeastern Iran. Health workers were observed indirectly during routine patient care in different shifts. Hand washing 
sinks were situated in patient's rooms, also, alcohol-based disinfectants were provided at an arm's reach for every bed or incubator.

Observational data were collected during 1 year, from June 2014 to July 2015 by the infection control teams. The details of contact with the patient, hand hygiene compliance, and the technique of hand washing among the health care workers were noted at "My 5 Moments for Hand Hygiene" of the World Health Organization (WHO) which explains the main moments that recommends health-care workers to clean their hands: 1 . before contact with the patient, 2. before clean/aseptic procedures, 3. after body fluid exposure/risk, 4. after touching a patient, and 5. after contact patient environment [6-8].

Data were collected by using the modified version of the WHO checklist and based on the use of both waterless, alcohol-based hand disinfectants and hand washing with soap was recorded and as a mean of hand hygienic practice in our study. Observers performed the activities of health workers at different times and locations. The observation of each health centre was starting at 8:00 a.m. and ending at 5:00 p.m. for two days. Also, to limit the bias, each unit was observed by a different pair of observer each day. The population of the study included health care workers, such as doctors, nurses, and others health workers in these hospitals.

\section{DATA ANALYSIS}

Hand hygiene compliance was calculated for doctors, nurses and other health workers in all 29 hospitals then reported as a percentage of the estimated opportunities observed for the specific hand hygiene procedure. Data from the checklist were entered into Microsoft Excel 2013 and imported into SPSS version 19 and analysed.

\section{RESULT}

In the present study, we evaluated a total of 92518 hand hygiene opportunities from 29 hospitals in the northeast of Iran, from June 2014 to July 2015 by the infection control teams. Our analysis shows overall compliance rates of $43.42 \%$ in health worker. Compliance rates differed by role: nurses $43 \%$, doctors $19 \%$ and other health workers $29 \%$ shown in Table 1.

Table 1. Compliance and Technique of Hand Hygiene among Health Workers (Doctors, Nurses and Others) in Northeast Iran Hospitals

\begin{tabular}{|c|c|c|c|c|c|c|c|c|c|c|c|c|c|c|c|}
\hline \multicolumn{3}{|c|}{ After body fluid exposure } & \multicolumn{3}{|c|}{$\begin{array}{l}\text { After contact patient } \\
\text { environment }\end{array}$} & \multicolumn{3}{|c|}{ After touching a patient } & \multicolumn{3}{|c|}{$\begin{array}{l}\text { Before clean/aseptic } \\
\text { procedures }\end{array}$} & \multicolumn{3}{|c|}{$\begin{array}{l}\text { Before contact with the } \\
\text { patient }\end{array}$} & \\
\hline HW & HR & Indec & HW & HR & Indec & HW & HR & Indec & HW & HR & Indec & HW & HR & Indec & \\
\hline 3455 & 2654 & 8700 & 2574 & 2398 & 8393 & 3645 & 3820 & 11415 & 1804 & 2371 & 8953 & 1532 & 3118 & 11900 & Nurses \\
\hline 1631 & 1189 & 3825 & 1450 & 1439 & 6519 & 577 & 680 & 2395 & 403 & 525 & 1640 & 336 & 564 & 4556 & Doctors \\
\hline 2667 & 2023 & 6307 & 1591 & 1460 & 6802 & 2082 & 1731 & 6480 & 365 & 462 & 1736 & 521 & 1159 & 7344 & Others \\
\hline
\end{tabular}

Hand hygiene compliance with respect to the five moments for hand hygiene were as follows: compliance before contact with the patient was $24.54 \%$, before clean/aseptic procedure was $12.75 \%$, after body fluid exposure was $19.5 \%$, after touching with patients was $21 \%$, and after contact patient environment was $22 \%$. Health workers were more prefer to wash their hands with soap and water procedure $(26.39 \%)$ instead of using alcohol-based disinfected (23\%).

\subsection{Hand hygiene compliance among nurses}

Nurses more likely prefer to clean their hand after body fluid exposure risk (70\%), secondly, after contact with a patient $(65 \%)$, then, before clean/aseptic procedures $(47 \%)$, and finally before clean/aseptic procedures $(39 \%)$.

\subsection{Hand hygiene compliance among doctors}

Doctors frequently prefer to wash their hands after exposure to body fluid risk (74\%), secondly, before a clean/aseptic procedure $(57 \%)$, thirdly after contact with a patient $(52 \%)$, fourthly after contact patient environment (44\%), and finally before touching patient (20\%). 


\section{DISCUSSION}

This observational study involved concealed observe of hand hygiene practices of health workers in the northeast hospitals of Iran display that the compliance of hand hygiene among the HCWs is poor. Hand hygiene, before and after contact with the patient or patient environment contact, before aseptic procedures, and after exposure to body fluid, which is WHO suggestions, is recommended in all guidelines published infection control and public health. Despite all these guidelines for hand hygiene in healthcare unite, the compliance with hand washing is still poor [9-12]. The present study aimed to define the compliance of hand hygiene among healthcare workers in the northeast of Iran.

There are several studies on the compliance of hand hygiene among HCWs. In Europe compliance with hand hygiene was different in the reports ranging from 33 to $65 \%$ [13, 14]. The study in Turkey showed that hand washing frequency among healthcare worker was $12.9 \%$ in an intensive care unit, also other observational studies show that hands were washed both before and after venipuncture in only $41(45.1 \%)$ cases $[15,16]$. In Iran, there are few studies on the compliance of hand hygiene. Moreover, this study attempted to measure the use of hand hygiene techniques based on the WHO five recommend.

The researchers in varies study considered that most of the health workers prefer to use hand hygiene after contact with the patient or the patients' environment. These findings lead to the assumption that HCWs prefer to protect themselves rather than patients [17-20]. The guidelines of WHO and CDC for hand hygiene in healthcare centre, and prevention suggest direct observation of compliance and measuring the use of hand hygiene products $[3,8,21]$.

Direct observation is a useful method to identify the strengths and weaknesses of hand hygiene, to mention the number of hand hygiene opportunities, for defining the techniques, and to provide feedback to healthcare workers $[20,18,22,23]$. The researchers of this study prefer to estimate the compliance of hand hygiene by direct observation like many studies in the literature. When the health workers know that they are under observation, hand hygiene efficiency usually improves [20]. However, in this study, health workers knew that they were under observation, but the compliance with hand hygiene was very low. Validated observers, also, randomly selecting the locations and day shifts of observation can minimize the observer bias.

In the present study we noticed that the health worker prefer to use soap and water compared to alcohol-based disinfected hand hygiene similar to some document in the literature; however, alcohol-based disinfectants provide a remaining effect that soap and water do not provide, it's maybe because of the unpleasant effects on the hands and lack of knowledge concerning its benefits.

\section{CONCLUSION}

This study notice evidence that hand hygiene compliance among health workers is so low. Although the hand hygiene methods are simple, that may be because of the lack of motivation and increased workload, so its need to design hand hygiene promotion programmes in this health centres. In addition, hand hygiene training and promotion in the hospital should include the introduction of alcohol-based hand rubs as an available and effective option for the hand hygiene.

\section{REFERENCES}

[1] Karaaslan A, Kepenekli Kadayifci E, Atıcı S, Sili U, Soysal A, Culha G, et al. "Compliance of Healthcare Workers with Hand Hygiene Practices in Neonatal and Pediatric Intensive Care Units: Overt Observation," Interdiscip Perspect Infect Dis. 2014;2014 :306478.

[2] Yawson AE, Hesse AA. "Hand Hygiene Practices and Resources in a Teaching Hospital in Ghana," J Infect.;7(04):338-47, 2013

[3] Boyce JM, Pittet D. "Guideline for Hand Hygiene in Health-Care Settings: Recommendations of the Healthcare Infection Control Practices Advisory Committee and the HICPAC/SHEA/APIC/IDSA Hand Hygiene Task Force," Am J Infect Control.;30(8):S1-S46, 2002.

[4] Safety WP, Organization WH. WHO Guidelines on Hand Hygiene in Health Care. 2009.

[5] Li Y, Wang Y, Yan D, Rao C. "Self-reported hand Hygiene Practices, and Feasibility and Acceptability of AlcoholBased Hand Rubs among Village Healthcare Workers in Inner Mongolia, China," J Hosp Infect.;90(4): 338-43, 2015.

[6] Organization WH. World Alliance for Safer Health Care. WHO Guidelines on Hand Hygiene in Health Care. First Global Patient Safety Challenge Clean Care is Safer Care. Geneva, Switzerland: Author Retrieved from http://whqlibdoc who int/publications/2009/9789241597906_eng pdf. 2009.

[7] Sproat L, Inglis T. "A Multicentre Survey of Hand Hygiene Practice in Intensive Care Units," J Hosp Infect.;26(2):137-48, 1994.

[8] Saito H, Borzykowski T, Kilpatrick C, Pires D, Allegranzi B, Pittet D. "It's in Your Hands-Prevent Sepsis in Health Care"; 5 May 2018 World Health Organization (WHO) SAVE LIVES: Clean Your Hands campaign. Clin Microbiol Infect. 2018. 
[9] Erasmus V, Daha TJ, Brug H, Richardus JH, Behrendt MD, Vos MC, et al. "Systematic Review of Studies on Compliance with Hand Hygiene Guidelines in Hospital Care," Infect Control Hosp Epidemiol.;31(3):283-94, 2010.

[10] Pittet D, Allegranzi B, Boyce J, "Experts WHOWAfPSFGPSCCGo. The World Health Organization guidelines on Hand Hygiene in Health Care and Their Consensus Recommendations," Infect Control Hosp Epidemiol.;30(7): 611-22, 2009.

[11] De França SR, Sant'Ana EA, Mafra ACCN, Prado M, Gagliardi GM, Edmond MB, et al. "The Impact of Isolation Precautions on Hand Hygiene Frequency by Healthcare Workers," Infect Control Hosp Epidemiol. 1-3, 2018.

[12] Seto WH, Cowling BJ, Cheung CW, Wong CY, Ching PT, Pittet D, et al. "Impact of the First Hand Sanitizing Relay World Record on Compliance With Hand Hygiene In A Hospital," Am J Infect Control. 43(3):295-7, 2015.

[13] Helder OK, van Goudoever JB, Hop WC, Brug J, Kornelisse RF. "Hand Disinfection in a Neonatal Intensive Care Unit: Continuous Electronic Monitoring Over A One-Year Period," BMC Infect Dis. 12(1):248, 2012.

[14] Schwadtke L, Graf K, Lutze B, Chaberny I. "Compliance with hand Hygiene Guidelines On Intensive Care Units at a University Medical Centre with Surgical Focus," Deutsche medizinische Wochenschrift (1946), 139(25-26): 1341-5, 2014.

[15] Metintas S, Akgun Y, Durmaz G, Kalyoncu C. "Prevalence and Characteristics of Nosocomial Infections in a Turkish University Hospital," Am J Infect Control. 32(7):409-13, 2004.

[16] Esen S, Leblebicioglu H, Group S. "Prevalence of Nosocomial Infections at Intensive Care Units in Turkey: a Multicentre 1-Day Point Prevalence Study," Scand J Infect Dis. 36(2):144-8, 2004.

[17] Al Ra'awji BA, Al-Mogbel ES, Alharbi LA, Alotaibi AK, Al-Qazlan FA, Saquib J. "Knowledge, Attitudes, and Practices of Health Care Workers Regarding Hand Hygiene Guidelines in Al-Qassim, Saudi Arabia: A Multicenter Study," Int J Health Sci (Qassim). 12(2), 2018.

[18] Haas J, Larson E. "Measurement of Compliance with Hand Hygiene," J Hosp Infect. 66(1):6-14, 2007.

[19] Różańska A, Bulanda M. "Demographic Characteristics of Patients and Their Assessment of Selected Hygienic Practices of Hospital Personnel in the Context of Safety Climate of Hospitalization," Am J Infect Control. 43(4):354-7, 2015.

[20] Magnus TP, Marra AR, Camargo TZS, da Silva Victor E, da Costa LSS, Cardoso VJ, et al. "Measuring Hand Hygiene Compliance Rates in Different Special Care Settings: A Comparative Study of Methodologies," Int J Infect Dis. 33:205-8, 2015.

[21] Pittet D, Allegranzi B, Sax H, Dharan S, Pessoa-Silva CL, Donaldson L, et al. "Evidence-based Model for Hand Transmission During Patient Care and the Role of Improved Practices," Lancet Infect Dis. 6(10):641-52, 2006.

[22] Van de Mortel T, Murgo M. "An Examination of Covert Observation And Solution Audit as Tools to Measure the Success of Hand Hygiene Interventions," Am J Infect Control. 34(3):95-9, 2006.

[23] Jeanes A, Dick J, Coen P, Drey N, Gould D. "Hand Hygiene Compliance Monitoring in Anaesthetics: Feasibility and validity," J Infect Prev. 2018:1757177418755306. 